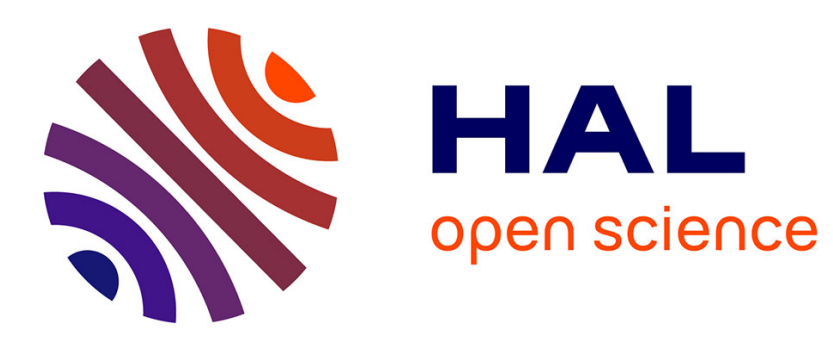

\title{
Intensity of preferences for bivariate risk apportionment
} David Crainich, Louis Eeckhoudt, Olivier Le Courtois

\section{To cite this version:}

David Crainich, Louis Eeckhoudt, Olivier Le Courtois. Intensity of preferences for bivariate risk apportionment. Journal of Mathematical Economics, 2020, 88, pp.153-160. 10.1016/j.jmateco.2020.03.007 . hal-03133126

\section{HAL Id: hal-03133126 \\ https://hal.science/hal-03133126}

Submitted on 6 Oct 2021

HAL is a multi-disciplinary open access archive for the deposit and dissemination of scientific research documents, whether they are published or not. The documents may come from teaching and research institutions in France or abroad, or from public or private research centers.
L'archive ouverte pluridisciplinaire HAL, est destinée au dépôt et à la diffusion de documents scientifiques de niveau recherche, publiés ou non, émanant des établissements d'enseignement et de recherche français ou étrangers, des laboratoires publics ou privés. 


\title{
Intensity of Preferences for Bivariate Risk Apportionment
}

\author{
David Crainich \\ CNRS (LEM, UMR 9221) and Iéseg School of Management \\ Louis Eeckhoudt \\ Iéseg School of Management and LEM (UMR 9221) \\ Olivier Le Courtois \\ emlyon business school
}

\begin{abstract}
Bivariate risk apportionment refers to the preference for spreading risks associated with the multiple attributes of an outcome across different states of the world rather than combining them in the same state. In this paper, we propose an intensity measure of this preference by extending to the bivariate case the concept of marginal rate of substitution between risks of different orders introduced by Liu and Meyer (2013). We show that the intensity measure of the preference for bivariate risk apportionment is characterized by bivariate risk attitudes in the Ross sense. The usefulness of our measure in understanding economic choices is illustrated by the analysis of two specific decisions: savings under environmental risk and medical treatment in the presence of diagnostic risks.
\end{abstract}

\section{JEL Classification: D81}

Keywords: Bivariate utility function; Increase in bivariate risks; Risk apportionment; Comparative risk aversion; Ross risk aversion. 


\section{Introduction}

Decision making usually occurs in the presence of risks affecting several aspects of individuals' well-being. Indeed, risk management strategies (such as precautionary savings, the purchase of insurance contracts, preventive actions, or portfolio choices) are often adopted while agents are exposed to risks associated with attributes of the utility function other than wealth (health state, environment, relatives' wealth or health state,...). Papers analyzing precautionary saving in bivariate (Courbage and Rey (2007)) or multivariate (Denuit, Eeckhoudt, and Menegatti (2011); Jouini, Napp, and Nocetti (2013); Courbage (2014)) settings, dealing with the effects of health risks on portfolio choices (Edwards, (2008); Crainich, Eeckhoudt, and Le Courtois (2017)), or examining investments improving future random health or environmental quality (Denuit, Eeckhoudt, and Menegatti (2011); Jouini, Napp, and Nocetti (2013)) offer illustrations of these types of decisions. Note that non-financial decisions have also been treated in the economic literature: the effect of random life expectancy on the intensity of a medical treatment in the presence of therapeutic risk has for instance been addressed in Bleichrodt, Crainich and Eeckhoudt (2011).

The above-mentioned papers can be classified into two categories: those analyzing the direction of changes and those addressing the intensity of changes in the decision variable once risks are either introduced or modified. Among the second category, Jouini, Napp, and Nocetti (2013) and Crainich, Eeckhoudt, and Le Courtois (2017) highlight that the trade-offs dictating agents' decisions depend on various measures of the intensity of multivariate risk attitude. In both papers, the latter are expressed as ratios wherein numerators are cross partial derivatives (of different orders) of the utility function while the denominator is the marginal utility of wealth. These intensity measures share the same denominator because the cost of the economic decision is purely financial in both contributions: forsaken current consumption that improves the future value of several attributes (Jouini, Napp, and Nocetti (2013)) and reduced expected returns when agents hold less risky assets in their financial portfolios (Crainich, Eeckhoudt, and Le Courtois (2017)). In other analysis, the denominators of the intensity measures of multivariate risk attitudes are second-order cross partial derivatives (see for instance Jouini, Napp, and Nocetti (2013) or Courbage (2014) who evaluate the effects of multivariate risk on the strength of precautionary saving).

In this paper, we show that the existing measures of the intensity of multivariate risk preferences are specific cases of a general approach as they all correspond to marginal rates of substitution between various orders changes in risk or in correlation. Our analysis is based on three important contributions in risk theory: 1) the interpretation of the signs of successive cross partial derivatives of the utility function exposed in Eeckhoudt, Rey, and Schlesinger (2007); 2 ) the concept of $n^{\text {th }}$ order increases in risk à la Ekern (1980);3) the rate of substitution between two stochastic changes introduced in Liu and Meyer (2013). Based on these concepts, we propose an intuitive interpretation of these intensity measures which - as highlighted in the paper - prove useful when analyzing risky decisions in the bivariate setting.

To provide these interpretations, we first make use of the bivariate preference ordering introduced by Eeckhoudt, Rey, and Schlesinger (2007). The latter concept generalizes that of correlation aversion (Richard (1975)), which refers to 
the preference for spreading wealth and health ${ }^{1}$ losses across states of the world instead of associating them in the same state. Richard (1975) indicates that correlation aversion corresponds to $u^{(1,1)}<0$ in the expected utility model $^{2}$. The generalization of this preference - called bivariated risk apportionment - is obtained when the dissociation principle is extended from losses to higher order zero-mean risks applied to both attributes ${ }^{3}$. In the expected utility model, Eeckhoudt, Rey, and Schlesinger (2007) make the connection between this preference ordering and the signs of successive cross partial derivatives of the utility function, that is, the signs of $u^{(2,1)}, u^{(1,2)}, u^{(2,2)}, \cdots, u^{\left(n_{1}, n_{2}\right)}$. Doing so, they establish the concept of $\left(n_{1}, n_{2}\right)^{\text {th }}$ degree correlation aversion.

We then apply the concept of an $n^{\text {th }}$ degree increase in risk (Ekern (1980)) to bivariate cases in order to obtain changes in bivariate distributions corresponding to the preference ordering defined in Eeckhoudt, Rey, and Schlesinger (2007). More precisely, while Ekern (1980) defines an $n^{\text {th }}$ degree increase in risk by keeping the $n-1$ first moments of the distribution constant, Denuit et al. (2013) define an $\left(n_{1}, n_{2}\right)^{\text {th }}$ degree increase in bivariate risk as the movement from one distribution to another such that the $\left(n_{1}, n_{2}\right)^{\text {th }}$ comoments of these two distributions differ and such that three constraints are satisfied. Namely, the bivariate distributions must have: 1) the same first $n_{1}$ moments for the marginal distribution of the first variable; 2 ) the same first $n_{2}$ moments for the marginal distribution of the second variable; 3$)$ the same first $\left(n_{1}+n_{2}-1\right)$ comoments. It can then be shown that every $\left(n_{1}, n_{2}\right)^{\text {th }}$ degree correlation averse agent dislikes $\left(n_{1}, n_{2}\right)^{\text {th }}$ degree increases in bivariate risks (or, using a different terminology, $\left(n_{1}, n_{2}\right)^{\text {th }}$ degree increases in correlation).

Equipped with this definition, we extend Liu and Meyer (2013) and propose a general measure of the intensity of preferences for bivariate risk apportionment. Liu and Meyer (2013) show that the existing measures $\left(\frac{-u^{\prime \prime}}{u^{\prime}}, \frac{-u^{\prime \prime \prime}}{u^{\prime \prime}}, \frac{u^{\prime \prime \prime}}{u^{\prime}}, \ldots\right)$ of the intensity of preferences towards risk in the univariate setting correspond to a rate of substitution between two increases in risk of different degrees. Specifically, suppose that $G(x)$ has more $n^{\text {th }}$ degree risk than $F(x)$, that $H(x)$ has more $m^{\text {th }}$ degree risk than $F(x)$ and that the agent is indifferent between $G(x)$ and $(1-T) F(x)+T H(x)$. Liu and Meyer (2013) indicate that $T$ is proportional to the ratio $\frac{u^{m}}{u^{n}}$ that corresponds therefore to a measure of the aversion towards increases in $n^{\text {th }}$ degree risk. As noted by these authors, $T$ is indeed "the weight that the decision maker is willing to put on $H(x)$ when forming a mixture of $F(x)$ and $H(x)$ to avoid having an $n^{\text {th }}$ degree risk increase from $F(x)$ to $G(x)$ instead". The same principle, applied to $\left(n_{1}, n_{2}\right)^{\text {th }}$ degree increases in bivariate risks, is used in our paper in order to provide a model-free interpretation of the measures of the intensity of bivariate risk preferences. In the expected utility model, the latter are expressed as ratios of cross partial derivatives of the utility function. As a result, they do not depend on utility scales and allow us to compare individuals' intensity of preferences for bivariate risk apportionment. Specifically, the concept of " $\frac{\left(n_{1}, n_{2}\right)}{\left(m_{1}, m_{2}\right)}{ }^{\text {th }}$ Ross more risk aversion" will be shown to

\footnotetext{
${ }^{1}$ Or any other attributes of the utility function.

${ }^{2}$ The following notation is adopted throughout the paper: $u^{\left(n_{1}, n_{2}\right)}$ refers to the $n_{1}^{\text {th }}$ and $n_{2}^{\text {th }}$ partial derivatives of the utility function with respect to its $1^{\text {st }}$ and $2^{\text {nd }}$ arguments, respectively.

${ }^{3}$ In their paper, Eeckhoudt, Rey, and Schlesinger (2007) only consider the transition from an extreme correlation to the other. Gollier (2019) generalizes the principle by evaluating via the concept of statistical concordance - the effect on utility of increases in higher-order correlation.
} 
allow the interpersonal comparison of the marginal rates of substitution between changes in bivariate risks.

The instrument we introduce generalize the existing measures of the intensity of bivariate preferences proposed by Jouini, Napp, and Nocetti (2013) and by Crainich, Eeckhoudt, and Le Courtois (2017). Their analyses exploit both the concept of an $\left(n_{1}, n_{2}\right)^{\text {th }}$ degree correlation aversion (Eeckhoudt, Rey, and Schlesinger, (2007)) and the technique used by Crainich and Eeckhoudt (2008) who measure the intensity of downside risk aversion in a univariate setting. Namely, the intensity of preference towards a distribution $F(x)$ compared to a distribution $G(x)$ is equivalent to the maximum amount of money one is willing to sacrifice in order to be exposed to $F(x)$ rather than to $G(x)$. As a result, these measures of the intensity of preferences in bivariate or multivariate settings are all based on the marginal utility of wealth. We extend this interpretation by stating that the compensation might take other forms, such as changes in marginal distributions corresponding to decreases in $m^{\text {th }}$ degree risk or changes in the distributions corresponding to decreases in $\left(n_{1}, n_{2}\right)^{\text {th }}$ degree correlation.

Our paper is organized as follows. We define in Section 1 the concept of $\left(n_{1}, n_{2}\right)^{\text {th }}$ degree changes in risk and associate preferences for theses changes to signs of various cross-derivatives of the utility function. We establish in Section 2 the measures of the intensity of preferences for $\left(n_{1}, n_{2}\right)^{\text {th }}$ degree changes in risk. We show in Section 3 how these intensity measures characterize economic choices. More precisely, we analyze savings decisions when agents are exposed to environmental risks and treatment intensity in the presence of diagnostic risks.

\section{Comparison of Bivariate Risks}

We consider a two dimensional random variable whose cumulative distribution function is denoted by $F$. We construct by successive integrations the function $F^{[k, h]}(.,$.$) . Indeed, we have: F^{[k, h]}(x, y)=\int_{a}^{x} F^{[k-1, h]}(s, y) d s$ and $F^{[k, h]}(x, y)=$ $\int_{a}^{y} F^{[k, h-1]}(x, t) d t$, where the initial point is $F^{[1,1]}(x, y)=F(x, y)$.

Following Denuit et al. (2013), we define the concept of more high-order bivariate degree risks, $\left("\left(n_{1}, n_{2}\right)^{\text {th }}\right.$ degree increases in risk"), which is an extension to the bivariate case of Ekern's definition of an " $n^{\text {th }}$ degree increase in risk".

Definition 1.1 (More $\left(n_{1}, n_{2}\right)^{\text {th }}$ degree risk). A distribution $G$ has more $\left(n_{1}, n_{2}\right)^{\text {th }}$ degree risk than a distribution $F$ if and only if, for all $(k, h) \leq\left(n_{1}, n_{2}\right)$,

$$
G^{[k, h]}(s, b)=F^{[k, h]}(s, b) \quad \forall s \in[a, b],
$$

and

and also

$$
G^{[k, h]}(b, t)=F^{[k, h]}(b, t) \quad \forall t \in[a, b],
$$

$$
G^{\left(n_{1}, n_{2}\right)}(s, t) \geq F^{\left(n_{1}, n_{2}\right)}(s, t) \quad \forall(s, t) \in[a, b]^{2} .
$$

Equipped with this definition, we extend Ekern (1980)'s result to the case of bivariate random vectors:

Proposition 1.2. Let $\boldsymbol{X}=\left(X_{1}, X_{2}\right)$ and $\boldsymbol{Y}=\left(Y_{1}, Y_{2}\right)$ be bivariate random vectors that are respectively $F$-distributed and $G$-distributed. When $G$ has more $\left(n_{1}, n_{2}\right)^{\text {th }}$ degree risk than $F$, then

$$
E\left(X_{1}^{k} X_{2}^{h}\right)=E\left(Y_{1}^{k} Y_{2}^{h}\right) \quad \forall(k, h)<\left(n_{1}, n_{2}\right),
$$


and

$$
(-1)^{n_{1}+n_{2}} E\left(X_{1}^{n_{1}} X_{2}^{n_{2}}\right) \leq(-1)^{n_{1}+n_{2}} E\left(Y_{1}^{n_{1}} Y_{2}^{n_{1}}\right) .
$$

Proof. For brevity, we omit the proof, which relies on multiple integrations by parts.

This proposition states that contrasting $\mathbf{X}$ and $\mathbf{Y}$ at order $\left(n_{1}, n_{2}\right)$ can be made by comparing the non-centered comoment of order $\left(n_{1}, n_{2}\right)$ when all of their lower-order non-centered moments and comoments are identical. These last constraints are expressed in Eq. (4). Note that there is no equivalence between (1), (2) and (3) on the one hand and (4) and (5) on the other: if any $\left(n_{1}, n_{2}\right)^{\text {th }}$ degree increase in risk implies that the bivariate distributions considered differ in their last comoment (their lower order comoments being equal), the opposite is not true. Therefore, the approach based on the concept of an $\left(n_{1}, n_{2}\right)^{\text {th }}$ degree increase in risk is more general than an approach based on the comoments.

We now come to the characterization of agents faced with bivariate choices.

Definition $1.3\left(\left(n_{1}, n_{2}\right)^{\text {th }}\right.$ degree risk aversion). An agent is $\left(n_{1}, n_{2}\right)^{\text {th }}$ degree risk averse if and only if

$$
(-1)^{n_{1}+n_{2}-1} u^{\left(n_{1}, n_{2}\right)}(s, t)>0 \quad \forall(s, t) \in[a, b]^{2} .
$$

Then, we can relate the comparisons of $\left(n_{1}, n_{2}\right)^{\text {th }}$ degree risks to the preferences of agents as follows:

Proposition 1.4. G has more $\left(n_{1}, n_{2}\right)^{\text {th }}$ degree risk than $F$ if and only if every $\left(n_{1}, n_{2}\right)^{\text {th }}$ degree risk averter prefers $F$ to $G$.

Proof. Let $\mathbf{X}$ and $\mathbf{Y}$ be bivariate random vectors that are F-distributed and G-distributed, respectively. The proof relies on the computation of

$$
E(u(\mathbf{X}))-E(u(\mathbf{Y}))=\int_{a}^{b} \int_{a}^{b} u(s, t) d F(s, t)-\int_{a}^{b} \int_{a}^{b} u(s, t) d G(s, t)
$$

via multiple integrations by parts, and on the study of its sign.

Proposition 1.4 describes the preferences that $\left(n_{1}, n_{2}\right)^{\text {th }}$ degree risk averse agents have towards bivariate distributions. But it says nothing about the intensity of these preferences or about the choices that two different $\left(n_{1}, n_{2}\right)^{\text {th }}$ degree risk averse agents might make. We address this question in the next section.

\section{Substitution of Bivariate Risks}

The transition from the concept of "direction" to that of "intensity" of preferences for bivariate risk apportionment is established by comparing two changes in distributions. We do so by extending to the bivariate case the intensity measure introduced in the univariate context by Liu and Meyer (2013). Assume that $G(x, y)$ has more $\left(n_{1}, n_{2}\right)^{\text {th }}$ degree risk than $F(x, y)$ and that $H(x, y)$ has more $\left(m_{1}, m_{2}\right)^{\text {th }}$ degree risk than $F(x, y)$. What is the value of $T$ such that an 
agent is indifferent between $G(x, y)$ and $(1-T) F(x, y)+T H(x, y)$ ? The higher $T$, the more the agent is sensitive to $\left(n_{1}, n_{2}\right)^{\text {th }}$ degree increases in risk relative to $\left(m_{1}, m_{2}\right)^{\text {th }}$ degree increases in risk. As a result, $T$ provides a measure of the intensity of the preference for $\left(n_{1}, n_{2}\right)^{\text {th }}$ risk apportionment. Note that the measure is "model-free" in the sense that it is not associated to a specific decision criterion. However, if agents behave according to the expected utility model, it is straightforward to show that for the agent $u$, the value of $T$ - denoted $T_{u}$ - is given by:

\section{Definition 2.1.}

$$
T_{u}=\frac{\int_{a}^{b} \int_{a}^{b} u(s, t)(d F(s, t)-d G(s, t))}{\int_{a}^{b} \int_{a}^{b} u(s, t)(d F(s, t)-d H(s, t))} .
$$

As in Liu and Meyer (2013), the proposed measure of intensity of bivariate risk preference is a ratio of two expected utility changes. While the Arrow-Pratt measure of risk aversion is sufficient to deal with the introduction of risks (i.e. the comparison between non-risky and risky situations), Ross (1981) has shown that a stronger measure of the increase in risk aversion might be required once increases in risks were addressed (i.e. the comparison two risky situations). In the paper, we show that the generalization of the Ross measure of "stronger risk aversion" is helpful when higher-order increases in bivariate risk are considered ${ }^{4}$. The Arrow-Pratt and Ross increases in higher-order bivariate risk aversion are respectively defined as follows:

Definition 2.2. $u$ is $\left(\left(n_{1}, n_{2}\right) /\left(m_{1}, m_{2}\right)\right)^{\text {th }}$ degree more risk averse than $v$ if, for all $(s, t) \in[a, b]^{2}$,

$$
\frac{(-1)^{n_{1}+n_{2}-1} u^{\left(n_{1}, n_{2}\right)}(s, t)}{(-1)^{m_{1}+m_{2}-1} u^{\left(m_{1}, m_{2}\right)}(s, t)} \geq \frac{(-1)^{n_{1}+n_{2}-1} v^{\left(n_{1}, n_{2}\right)}(s, t)}{(-1)^{m_{1}+m_{2}-1} v^{\left(m_{1}, m_{2}\right)}(s, t)},
$$

whereas $u$ is $\left(\left(n_{1}, n_{2}\right) /\left(m_{1}, m_{2}\right)\right)^{\text {th }}$ degree Ross more risk averse than $v$ if, for all $(s, t) \in[a, b]^{2}$ and for all $(w, z) \in[a, b]^{2}$,

$$
\frac{(-1)^{n_{1}+n_{2}-1} u^{\left(n_{1}, n_{2}\right)}(s, t)}{(-1)^{m_{1}+m_{2}-1} u^{\left(m_{1}, m_{2}\right)}(w, z)} \geq \frac{(-1)^{n_{1}+n_{2}-1} v^{\left(n_{1}, n_{2}\right)}(s, t)}{(-1)^{m_{1}+m_{2}-1} v^{\left(m_{1}, m_{2}\right)}(w, z)} .
$$

These definitions allow the interpersonal comparison of the propensity to trade $\left(n_{1}, n_{2}\right)^{\text {th }}$ order changes against $\left(m_{1}, m_{2}\right)^{\text {th }}$ order changes in risk. Combining what precedes, the following Proposition can indeed be established:

Proposition 2.3. We consider two agents $u$ and $v$ that are each both $\left(n_{1}, n_{2}\right)^{\text {th }}$ degree risk averse and $\left(m_{1}, m_{2}\right)^{\text {th }}$ degree risk averse. The following statements are equivalent:

(i) $u$ is $\left(\left(n_{1}, n_{2}\right) /\left(m_{1}, m_{2}\right)\right)^{\text {th }}$ degree Ross more risk averse than $v$ on $[a, b]^{2}$, if there exists $\lambda>0$ such that $\frac{u^{\left(n_{1}, n_{2}\right)}(s, t)}{v^{\left(n_{1}, n_{2}\right)}(s, t)} \geq \lambda \geq \frac{u^{\left(m_{1}, m_{2}\right)}(w, z)}{v^{\left(m_{1}, m_{2}\right)}(w, z)}$ for all $(s, t) \in[a, b]^{2}$ and $(w, z) \in[a, b]^{2}$.

\footnotetext{
${ }^{4}$ In the univariate setting, Liu and Neilson (2019) recently indicated that higher-order risk aversion in the Ross sense characterizes three behavioral notions of comparative risk attitude: the risk premium approach (Pratt, (1981)), the probability premium approach (Pratt, (1981)) and the comparative statics approach (Jindapon and Neilson, (2007)).
} 
(ii) There exist $\lambda>0$ and $\phi:[a, b]^{2} \rightarrow \mathbb{R}$ such that $u=\lambda v+\phi$ and such that $(-1)^{m_{1}+m_{2}-1} \phi^{\left(m_{1}, m_{2}\right)}(s, t) \leq 0$ and $(-1)^{n_{1}+n_{2}-1} \phi^{\left(n_{1}, n_{2}\right)}(s, t) \geq 0$ for all $(s, t) \in[a, b]^{2}$.

(iii) $T_{u} \geq T_{v}$ for all $F, G$, and $H$ such that $G$ has more $\left(n_{1}, n_{2}\right)^{\text {th }}$ degree risk than $F$ and $H$ has more $\left(m_{1}, m_{2}\right)^{\text {th }}$ degree risk than $F$

Proof. See the appendix.

Part (i) of Proposition 2.3 determines the condition under which an individual whose preferences are represented by the utility function $u$ is $\left(\left(n_{1}, n_{2}\right) /\left(m_{1}, m_{2}\right)\right)^{\text {th }}$ degree Ross more risk averse than another individual whose preferences are represented by $v$. Parts (ii) of Proposition 2.3 defines the transformation of the bivariate utility function that preserves this partial order. Part (iii) of the Proposition compares the intensity of preferences for $\left(n_{1}, n_{2}\right)^{\text {th }}$ order bivariate risk apportionment of individuals $u$ and $v$. The equivalence between parts (i), (ii) and (iii) of Proposition 2.3 establishes that the propensity to trade $\left(n_{1}, n_{2}\right)^{\text {th }}$ order changes against $\left(m_{1}, m_{2}\right)^{\text {th }}$ order changes in risk, i.e. the intensity of preference for $\left(n_{1}, n_{2}\right)^{\text {th }}$ order bivariate risk apportionment is characterized by the concept of " $\left(\left(n_{1}, n_{2}\right) /\left(m_{1}, m_{2}\right)\right)^{\text {th }}$ degree Ross more risk aversion".

\section{Bivariate High-Order Economic Decisions}

In this section, we show how the concept of "Ross more risk aversion" that characterizes the intensity of preference for bivariate risk apportionment can be useful in explaining economic decisions. The illustrations we propose are based on the way agents react to changes in the distribution of a variable $h$, in the spirit of the technique introduced by Jindapon and Neilson (2007). Specifically, we suppose that agents are exposed to a distribution $Z(h, t)$, which is a weighted average between two distributions $X(h)$ and $Y(h)$ whose supports are both contained in $[a, b]$ and such that $Z(h, t)=(1-t) Y(h)+t X(h)$. We also assume that $Y \succ_{n} X$, that is, $X$ is an $n^{\text {th }}$ degree increase in risk $\grave{a}$ la Ekern (1980) with respect to $Y$. In what follows, $X^{0}(h)$ and $Y^{0}(h)$ denote density functions, $X^{1}(h)$ and $Y^{1}(h)$ denote cumulative density functions, and, more generally, we have for $N=X, Y, Z$ :

$$
N^{n}(h)=\int_{a}^{b} N^{n-1}(h) d h .
$$

Following Ekern (1980), the distribution $Y$ is an $n^{\text {th }}$ degree decrease in risk over the distribution $X$ if and only if

$$
Y^{k}(b)=X^{k}(b) \quad \text { for } k=1,2, \ldots n
$$

and

$$
Y^{n}(h) \leq X^{n}(h) \quad \forall h \in[a, b] \quad \text { with strong inequality for some } h .
$$

The first condition implies that the $n-1$ first moments of the distributions $X$ and $Y$ are equal. 


\subsection{A saving decision}

Consider the following savings problem. An agent lives two periods during which she earns an identical income $(w)$. Besides this income, the environment quality $(h)$ she enjoys also enters in her utility function so that her preferences are represented by $u(w, h)$. We suppose that the utility of wealth and the utility of environmental quality are both increasing and concave: $u^{(1,0)}>0, u^{(0,1)}>0$, $u^{(2,0)}<0$, and $u^{(0,2)}<0$. The agent has the opportunity to transfer money through savings, denoted by $s$, from period 1 to period 2 .

To simplify this problem, we suppose without loss of generality that the agent's utility function is the same across periods and that the interest rate and the rate of intertemporal preference are both null. Suppose also that the saving decision is made under an environmental risk resulting from policies implemented by public authorities. Specifically, the environmental policy we consider is related to the intensity of the use (denoted by $t$ ) of a non-polluting technology which, however, involves some risks as it potentially leads to environmental damages. The initial distribution of the environmental quality is given by $Z(h, t)=(1-t) Y(h)+t X(h)$. Any intensification in the use of the technology simultaneously improves the average environmental quality at a constant rate $\alpha$ and creates an $n^{\text {th }}$ degree deterioration in the environmental risk, because $Y \succ_{n} X$. A special case - which corresponds to $n=3$ - is that of nuclear technologies, which improve the average environmental quality but also entail catastrophic risk, that is, huge potential damage with a low probability. More generally, the agent's maximization problem is given by:

$$
\max _{s}\left[u(w-s, h)+\int_{a}^{b} u(w+s, h+\alpha t) Z^{0}(h, t) d h\right] .
$$

The first order condition for this program is given by:

$$
E U_{s}=-u^{(1,0)}\left(w-s^{*}, h\right)+\int_{a}^{b} u^{(1,0)}\left(w+s^{*}, h+\alpha t\right) Z^{0}(h, t) d h=0 .
$$

The second order condition is satisfied because risk aversion towards financial risks has been assumed $\left(u^{(2,0)}<0\right)$ :

$$
E U_{s s}=u^{(2,0)}\left(w-s^{*}, h\right)+\int_{a}^{b} u^{(2,0)}\left(w+s^{*}, h+\alpha t\right) Z^{0}(h, t) d h<0 .
$$

We use the implicit function theorem in order to determine the conditions under which the agent increases her savings in reaction to the intensification of the environmental policy $t$ by public authorities:

$$
\frac{d s}{d t}=-\frac{\frac{\partial E U_{s}}{\partial t}}{\frac{\partial E U_{s}}{\partial s}}=\frac{\frac{\partial E U_{s}}{\partial t}}{-E U_{s s}}
$$

Since $E U_{s s}<0$, the sign of $\frac{d s}{d t}$ is the same as that of $\frac{\partial E U_{s}}{\partial t}$, where

$$
\begin{aligned}
\frac{\partial E U_{s}}{\partial t}=\alpha & \int_{a}^{b} u^{(1,1)}(w+s, h+\alpha t) Z^{0}(h, t) d h \\
& +\int_{a}^{b} u^{(1,0)}(w+s, h+\alpha t)\left[X^{0}(h)-Y^{0}(h)\right] d h .
\end{aligned}
$$


Suppose first that $X$ is a mean preserving spread of $Y$ or, equivalently, that an increase in $t$ corresponds to a second order increase in risk. Applying integration by parts twice to re-express the second term of $\frac{\partial E U_{s}}{\partial t}$, we obtain:

$$
\begin{aligned}
\frac{\partial E U_{s}}{\partial t}=\alpha & \int_{a}^{b} u^{(1,1)}(w+s, h+\alpha t) Z^{0}(h, t) d h \\
& +\int_{a}^{b} u^{(1,2)}(w+s, h+\alpha t)\left[X^{2}(h)-Y^{2}(h)\right] d h
\end{aligned}
$$

where $Y^{2}(h) \leq X^{2}(h) \forall h \in[a, b]$, by definition of a second order increase in risk.

If $u^{(1,1)}$ and $u^{(1,2)}$ have the same sign, it is straightforward to determine the way savings change with the implementation of the environmental policy: agents increase savings $\left(\frac{\partial E U_{s}}{\partial t}>0\right)$ if $u^{(1,1)}>0$ and $u^{(1,2)}>0$ and decrease savings $\left(\frac{\partial E U_{s}}{\partial t}<0\right)$ if $u^{(1,1)}<0$ and $u^{(1,2)}<0$. If the cross-derivatives of the utility function alternate in signs, the effect of the environmental policy on their saving decision depends on the intensity of $\left(\frac{1,2}{1,1}\right)^{\text {th }}$ bivariate risk preferences:

$$
\frac{\partial E U_{s}}{\partial t} \gtreqless 0 \Leftrightarrow-\frac{\int_{a}^{b} u^{(1,2)}(w+s, h+\alpha t)\left[X^{2}(h)-Y^{2}(h)\right] d h}{\int_{a}^{b} u^{(1,1)}(w+s, h+\alpha t) Z^{0}(h, t) d h} \gtreqless \alpha .
$$

Specifically, consider two agents $u$ and $v$, where agent $u$ is $\left(\frac{1,2}{1,1}\right)^{\text {th }}$ Ross more risk averse than agent $v$, so that the following condition is met:

$$
-\frac{u^{(1,2)(w, e)}}{u^{(1,1)(w, h)}} \geq-\frac{v^{(1,2)(w, e)}}{v^{(1,1)(w, h)}} \quad \forall e, h \in[a, b] .
$$

In line with Jindapon and Neilson (2007), it can be shown that this inequality implies:

$$
-\frac{u^{(1,2)(w, e)}}{\int_{a}^{b} u^{(1,1)}(w, h) Z^{0}(h, t) d h} \geq-\frac{v^{(1,2)(w, e)}}{\int_{a}^{b} v^{(1,1)}(w, h) Z^{0}(h, t) d h} \quad \forall e \in[a, b],
$$

which in turn implies:

$$
-\frac{\int_{a}^{b} u^{(1,2)}(w, h)\left[X^{2}(h)-Y^{2}(h)\right] d h}{\int_{a}^{b} u^{(1,1)}(w, h) Z^{0}(h, t) d h} \geq-\frac{\int_{a}^{b} v^{(1,2)}(w, h)\left[X^{2}(h)-Y^{2}(h)\right] d h}{\int_{a}^{b} v^{(1,1)}(w, h) Z^{0}(h, t) d h} .
$$

As a result, if $-\frac{u^{(1,2)(w, e)}}{u^{(1,1)(w, h)}} \geq \frac{v^{(1,2)(w, e)}}{v^{(1,1)(w, h)}} \quad \forall e, h \in[a, b]$, one can find values of $\alpha$ such that $u$ increases savings while $v$ decreases it as public authorities intensify the environmental policy $t$.

The interpretation of the signs of various cross derivatives of a bivariate utility function provided by Eeckhoudt, Rey and Schlesinger (2007) can be used in order to understand this result. When $n=2$, the intensification of the public policy both improves the average environmental quality and increases $2^{\text {nd }}$ order environmental risk. Following Eeckhoudt, Rey, and Schlesinger (2007): 1) sure improvements in the environmental quality reduce the marginal utility of wealth if $\left.u^{(1,1)}<0 ; 2\right)$ increases in $2^{\text {nd }}$ order environmental risk increase the marginal 
utility wealth if $u^{(1,2)}>0$. Therefore, the environmental policy has two opposite effects on savings. Its final effect then depending on the relative sensitivity of the marginal utility of wealth to these two changes, which corresponds to the intensity of $\left(\frac{1,2}{1,1}\right)^{\text {th }}$ bivariate risk.

Note finally that when changing $t$, different risks are attached to different environmental quality levels $h+\alpha t$. As a result, if $-\frac{u^{(1,2)(w+s, h)}}{u^{(1,1)(w+s, h)}}>\frac{v^{(1,2)(w+s, h)}}{v^{(1,1)(w+s, h)}}$ while $-\frac{u^{(1,2)(w+s, h+\alpha t)}}{u^{(1,1)(w+s, h+\alpha t)}}<\frac{v^{(1,2)(w+s, h+\alpha t)}}{v^{(1,1)(w+s, h+\alpha t)}}$, the effects of the environmental policy on the savings made by individuals $u$ and $v$ cannot be compared. This is why $\left(\frac{1,2}{1,1}\right)^{\text {th }}$ Ross risk aversion is required in this particular illustration.

Using the same technique, it can be shown that environmental policies intensifying the use of nuclear energy $(n=3)$, lead to increased (resp. reduced) savings by agent $u$ (resp. $v$ ) if $u$ is more $\left(\frac{1,3}{1,1}\right)^{\text {th }}$ Ross risk averse than $v$. More generally, when the intensification of $t$ corresponds to a $n^{\text {th }}$ order increases in risk $\left(Y \succ_{n} X\right)$, savings decisions depends on $\left(\frac{1, n}{1,1}\right)^{\text {th }}$ Ross risk aversion.

\subsection{A treatment decision}

Consider a patient whose preferences are represented by a bivariate utility function $u(w, h)$ that depends on wealth $w$ and health $h$. The utility of wealth and the utility of health are supposed to be both increasing and concave: $u^{(1,0)}>0$, $u^{(0,1)}>0, u^{(2,0)}<0$, and $u^{(0,2)}<0$. This patient suffers from a disease whose severity is random: the distribution $Z(h, t)$ of his health state $h$ is given by $Z(h, t)=(1-t) Y(h)+t X(h)$ with $Y \succ_{n} X$. Therefore, increases in $t$ correspond to $n^{\text {th }}$ order increases in health risk. Patients perform a treatment whose intensity is denoted by $z$ and whose constant unitary cost and benefit are denoted by $\alpha$ and $\beta$, respectively. The patient chooses an intensity of treatment that maximizes his expected utility:

$$
\max _{z} \int_{a}^{b} u(w-\alpha z, h+\beta z) Z^{0}(h, t) d h .
$$

The first order condition of this program is given by:

$$
\begin{aligned}
E U_{z}=-\alpha & \int_{a}^{b} u^{(1,0)}(w-\alpha z, h+\beta z) Z^{0}(h, t) d h \\
& \quad+\beta \int_{a}^{b} u^{(0,1)}(w-\alpha z, h+\beta z) Z^{0}(h, t) d h=0 .
\end{aligned}
$$

The second order condition is satisfied since risk aversion towards both financial and health risks has been assumed $\left(u^{(2,0)}<0\right.$ and $\left.u^{(0,2)}<0\right)$ :

$$
\begin{aligned}
E U_{z z}= & \alpha^{2} \int_{a}^{b} u^{(2,0)}(w-\alpha z, h+\beta z) Z^{0}(h, t) d h \\
& +\beta^{2} \int_{a}^{b} u^{(0,2)}(w-\alpha z, h+\beta z) Z^{0}(h, t) d h<0 .
\end{aligned}
$$

Are patients more or less treatment prone in case of $n^{\text {th }}$ order increases in the severity of the disease? The change in treatment intensity is given by the 
sign of:

$$
\frac{d z}{d t}=-\frac{\frac{\partial E U_{z}}{\partial t}}{\frac{\partial E U_{z}}{\partial z}}=\frac{\frac{\partial E U_{z}}{\partial t}}{-E U_{z z}}
$$

which is identical to the sign of $\frac{\partial E U_{z}}{\partial t}$, where:

$$
\begin{aligned}
\frac{\partial E U_{z}}{\partial t}=- & \alpha \int_{a}^{b} u^{(1,0)}(w-\alpha z, h+\beta z)\left[X^{0}(h)-Y^{0}(h)\right] d h \\
& +\beta \int_{a}^{b} u^{(0,1)}(w-\alpha z, h+\beta z)\left[X^{0}(h)-Y^{0}(h)\right] d h .
\end{aligned}
$$

Applying the integration by parts $n$ times in order to re-express the two terms of $\frac{\partial E U_{z}}{\partial t}$, we obtain:

$$
\begin{aligned}
\frac{\partial E U_{z}}{\partial t}=- & \alpha(-1)^{n} \int_{a}^{b} u^{(1, n)}(w-\alpha z, h+\beta z)\left[X^{n}(h)-Y^{n}(h)\right] d h \\
& +\beta(-1)^{n} \int_{a}^{b} u^{(0, n+1)}(w-\alpha z, h+\beta z)\left[X^{n}(h)-Y^{n}(h)\right] d h,
\end{aligned}
$$

where $Y^{n}(h) \leq X^{n}(h) \forall h \in[a, b]$, by definition of an $n^{\text {th }}$ order increase in risk.

When $u^{(1, n)}$ and $u^{(0, n+1)}$ have different signs, it is straightforward to show that $n^{\text {th }}$ order increases in the severity of disease lead to more treatment when $u^{(1, n)}<0$ and $u^{(0, n+1)}>0$ and have the opposite effect (i.e. they reduce the treatment intensity) when $u^{(1, n)}>0$ and $u^{(0, n+1)}<0$. When these derivatives of the utility function have the same sign, changes in the treatment intensity consecutive to $n^{\text {th }}$ order increases in the severity of the disease depend on the intensity of $\left(\frac{1, n}{0, n+1}\right)^{\text {th }}$ multivariate risk aversion. Re-arranging the last expression, we indeed obtain:

$$
\frac{\partial E U_{z}}{\partial t} \gtreqless 0 \Leftrightarrow \int_{a}^{b} \frac{u^{(1, n)}(w-\alpha z, h+\beta z)}{u^{(0, n+1)}(w-\alpha z, h+\beta z)}\left[X^{0}(h)-Y^{0}(h)\right] d h \lesseqgtr \frac{\beta}{\alpha},
$$

when $u^{(1, n)}$ and $u^{(0, n+1)}$ are both positive.

Similarly, we have:

$$
\frac{\partial E U_{z}}{\partial t} \gtreqless 0 \Leftrightarrow \int_{a}^{b} \frac{u^{(1, n)}(w-\alpha z, h+\beta z)}{u^{(0, n+1)}(w-\alpha z, h+\beta z)}\left[X^{0}(h)-Y^{0}(h)\right] d h \gtreqless \frac{\beta}{\alpha},
$$

when $u^{(1, n)}$ and $u^{(0, n+1)}$ are both negative.

To understand this result, let us consider increases in the spread of the health distribution (corresponding to $n=2$ ). This change increases the marginal utility of health of prudent individuals $\left(u^{(0,3)}>0\right.$; see Eeckhoudt and Schlesinger (2006)) and simultaneously increases the marginal utility of wealth of "crossprudent in wealth" individuals $\left(u^{(1,2)}>0\right.$; see Eeckhoudt, Rey and Schlesinger (2007)). The global effect on the treatment intensity depends on the comparison between: 1) the relative sensitivity of the marginal utility of wealth and of health to this change $\left.\left(\frac{u^{(1,2)}}{u^{(0,3)}}\right) ; 2\right)$ the relative unitary cost and benefit of the treatment $\left(\frac{\beta}{\alpha}\right)$. 
Note that since the increase in risk affects the marginal utility of wealth and of health evaluated at the same point (the wealth level $w-\alpha z$ and the health level $h+\beta z$ ), interpersonal comparisons can be established through the concept of Arrow-Pratt bivariate risk aversion (i.e. the concept of Ross bivariate risk aversion is not required to compare the effects of changes in risk on the treatment intensity selected by two individuals). More precisely, for any $n$, if $u^{(1, n)}$ and $u^{(0, n+1)}$ are both positive, and if $u$ is $\left(\frac{1, n}{0, n+1}\right)^{\text {th }}$ Arrow-Pratt more risk averse than $v$, one can find values of $\alpha$ and $\beta$ such that $n^{\text {th }}$ order increases in the severity of the disease reduce (resp. increase) the treatment intensity selected by $u$ (resp. $v$ ). Likewise, for some values of $\alpha$ and $\beta$, the same changes in risk increase the treatment performed by $u$ while reducing that performed by $v$ when $u^{(1, n)}$ and $u^{(0, n+1)}$ are both negative.

\section{Conclusion}

Decision-makers consider various aspects of their well-being, such as wealth, health, or environment quality, when they make choices that modify the risks they are exposed to. We extend Liu and Meyer (2013) to the bivariate case to show that the propensity to trade $\left(n_{1}, n_{2}\right)^{\text {th }}$ order changes against $\left(m_{1}, m_{2}\right)^{\text {th }}$ order changes in risk measure the intensity of preference for $\left(n_{1}, n_{2}\right)^{\text {th }}$ order bivariate risk apportionment. Besides, the interpersonal comparisons of the intensity of these preferences is characterized by the concept of " $\left(\left(n_{1}, n_{2}\right) /\left(m_{1}, m_{2}\right)\right)^{\text {th }}$ degree Ross more risk aversion". We also show that these concepts can be useful in understanding how individuals make, for instance, savings decisions when they anticipate environmental risks or treatment decisions in the case of diagnostic risks.

In a recent contribution, Jindapon, Liu and Neilson (2019) compare the intensity of risk apportionment preferences of two individuals in the univariate setting. Instead of using the marginal rate of substitution between two increases in risk as we do in our paper, they define another measure of the intensity of preference for $n^{\text {th }}$ degree risk apportionment, namely the $\left(\frac{n}{m}\right)^{\text {th }}$ degree probability premium. The main result of their paper is that increases in $\left(\frac{n}{m}\right)^{\text {th }}$ degree Ross and in $\left(\frac{n}{m}\right)^{\text {th }}$ degree Arrow-Pratt risk aversion are, respectively, sufficient and necessary for comparing preferences for $n^{\text {th }}$ degree risk apportionment. Establishing the relative merits of these two ways of measuring the intensity of preferences for bivariate risk apportionment would constitute a natural extension of the present paper. This issue is left for future research.

\section{Acknowledgements}

The research leading to these results received funding from the French Agence Nationale de la Recherche (ANR), under grant ANR-17-CE03-0008-01 (project INDUCED) 


\section{References}

Bleichrodt, H., D. Crainich, and L. Eeckhoudt (2011): "The Effect of Comorbidities on Treatment Decisions," Journal of Health Economics, 22(5), 805-820.

Courbage, C. (2014): "Saving Motives and Multivariate Precautionary Premia," Decisions in Economics and Finance, 37(2), 385-391.

Courbage, C., and B. Rey (2007): "Precautionary Saving in the Presence of Other Risks," Economic Theory, 32(2), 417-424.

Crainich, D., and L. Eeckhoudt (2008): "On the Intensity of Downside Risk Aversion," Journal of Risk and Uncertainty, 36, 267-276.

Crainich, D., L. Eeckhoudt, and O. Le Courtois (2017): "Health and Portfolio Choices: a Diffidence Approach," European Journal of Operational Research, 259(1), 273-279.

Denuit, M., and L. Eeckhoudt (2010): "A General Index of Absolute Risk Attitude," Management Science, 56, 712-715.

Denuit, M., L. Eeckhoudt, and M. Menegatti (2011): "Correlated Risks, Bivariate Utility and Optimal Choices," Economic Theory, 46(1), 39-54.

Denuit, M., L. Eeckhoudt, I. Tsethin, and R. L. Winkler (2013): "Multivariate Concave and Convex Stochastic Dominance," in Risk Measures and Attitudes, ed. by F. Biagini, A. Richter, and H. Schlesinger, pp. 11-32. Springer, EAA Series.

Edwards, R. (2008): "Health Risk and Portfolio Choice," Journal of Business and Economic Statistics, 26(4), 472-485.

Eeckhoudt, L., B. Rey, And H. Schlesinger (2007): "A Good Sign for Multivariate Risk Taking," Management Science, 53, 117-124.

Eeckhoudt, L., and H. Schlesinger (2006): "Putting Risk in its Proper Place," American Economic Review, 96(1), 280-289.

Ekern, S. (1980): "Increasing Nth Degree Risk," Economics Letters, 6, 329333.

Gollier, C. (2019): "A general theory of risk apportionment," TSE Working Paper 19-1003.

Jindapon, P., L. LiU, and L. W. Neilson (2019): "Comparative Risk Apportionment," Working Paper.

JindAPON, P., AND W. NeILSON (2007): "Higher-order generalizations of Arrow-Pratt and Ross risk aversion: a comparative statics approach," Journal of Economic Theory, 136(1), 719-728.

Jouini, E., C. NAPp, And D. Nocetti (2013): "On Multivariate Prudence," Journal of Economic Theory, 148, 1255-1267. 
Liu, L., And J. Meyer (2013): "Substituting One Risk increase for Another: A Method for Measuring Risk Aversion," Journal of Economic Theory, 148(6), $2706-2718$.

LiU, L., And W. Neilson (2019): "Alternative Approaches to nth-degree Risk Aversion," Management Science, forthcoming.

Pratt, J. (1981): "Risk aversion in the small and in the large," Econometrica, $32(1-2), 122-136$.

Richard, S. (1975): "Multivariate Risk Aversion, Utility Independence and Separable Utility Functions," Management Science, 42(1), 12-21.

Ross, S. A. (1981): "Some Stronger Measures of Risk Aversion in the Small and the Large with Applications," Econometrica, 49(3), 621-638.

\section{Appendix: Proof of Proposition 2.3}

The equivalences are shown by generalizing the arguments in Liu and Meyer (2013).

$(i) \Rightarrow(i i)$. Using $\lambda$ defined in $(i)$, we construct $\phi$ as follows:

$$
\phi(s, t)=u(s, t)-\lambda v(s, t) \quad \forall(s, t) \in[a, b]^{2} .
$$

We readily check that

$$
\begin{aligned}
& (-1)^{m_{1}+m_{2}-1} \phi^{\left(m_{1}, m_{2}\right)}(s, t) \\
& \quad=(-1)^{m_{1}+m_{2}-1} u^{\left(m_{1}, m_{2}\right)}(s, t)-\lambda(-1)^{m_{1}+m_{2}-1} v^{\left(m_{1}, m_{2}\right)}(s, t) \leq 0
\end{aligned}
$$

and

$$
\begin{aligned}
& (-1)^{n_{1}+n_{2}-1} \phi^{\left(n_{1}, n_{2}\right)}(s, t) \\
& \quad=(-1)^{n_{1}+n_{2}-1} u^{\left(n_{1}, n_{2}\right)}(s, t)-\lambda(-1)^{n_{1}+n_{2}-1} v^{\left(n_{1}, n_{2}\right)}(s, t) \geq 0 .
\end{aligned}
$$

(ii) $\Rightarrow($ iii $)$. From the definition of $T_{u}$, we have:

$$
\int_{a}^{b} \int_{a}^{b} u(s, t)\left[\left(1-T_{u}\right) d F(s, t)+T_{u} d H(s, t)\right]=\int_{a}^{b} \int_{a}^{b} u(s, t) d G(s, t) .
$$

Then,

$$
\int_{a}^{b} \int_{a}^{b} u(s, t) d G(s, t)=\int_{a}^{b} \int_{a}^{b}(\lambda v(s, t)+\phi(s, t)) d G(s, t)
$$

and

$$
\int_{a}^{b} \int_{a}^{b}(\lambda v(s, t)+\phi(s, t)) d G(s, t) \leq \int_{a}^{b} \int_{a}^{b} \lambda v(s, t) d G(s, t)+\int_{a}^{b} \int_{a}^{b} \phi(s, t) d F(s, t)
$$


because $\phi$ shows $\left(n_{1}, n_{2}\right)^{\text {th }}$ degree risk aversion. Further, using the definition of $T_{v}$ and the fact that $\phi$ shows $\left(m_{1}, m_{2}\right)^{\text {th }}$ degree risk taking, we have:

$$
\begin{aligned}
& \int_{a}^{b} \int_{a}^{b} \lambda v(s, t) d G(s, t)+\int_{a}^{b} \int_{a}^{b} \phi(s, t) d F(s, t) \leq \\
& \int_{a}^{b} \int_{a}^{b} \lambda v(s, t)\left[\left(1-T_{v}\right) d F(s, t)+T_{v} d H(s, t)\right]+\int_{a}^{b} \int_{a}^{b} \phi(s, t)\left[\left(1-T_{v}\right) d F(s, t)+T_{v} d H(s, t)\right],
\end{aligned}
$$

so that

$$
\int_{a}^{b} \int_{a}^{b} \lambda v(s, t) d G(s, t)+\int_{a}^{b} \int_{a}^{b} \phi(s, t) d F(s, t) \leq \int_{a}^{b} \int_{a}^{b} u(s, t)\left[\left(1-T_{v}\right) d F(s, t)+T_{v} d H(s, t)\right] .
$$

Recombining the above equalities and inequalities shows that $T_{u} \geq T_{v}$.

$($ iii $) \Rightarrow(i)$. By integration by parts, we can show that

$$
\begin{aligned}
\int_{a}^{b} \int_{a}^{b}(-1)^{k+h-1} u^{(k, h)}(s, t)\left(G^{[k, h]}(s, t)-F^{[k, h]}(s, t)\right) d s d t \\
\quad \int_{a}^{b}\left[(-1)^{k+h-1} u^{(k, h)}(s, t)\left(G^{[k+1, h]}(s, t)-F^{[k+1, h]}(s, t)\right)\right]_{a}^{b} d t \\
\quad-\int_{a}^{b} \int_{a}^{b}(-1)^{k+h-1} u^{(k+1, h)}(s, t)\left(G^{[k+1, h]}(s, t)-F^{[k+1, h]}(s, t)\right) d s d t .
\end{aligned}
$$

Using conditions (1) and (2), we obtain:

$$
\begin{aligned}
& \int_{a}^{b} \int_{a}^{b}(-1)^{k+h-1} u^{(k, h)}(s, t)\left(G^{[k, h]}(s, t)-F^{[k, h]}(s, t)\right) d s d t= \\
& \quad \int_{a}^{b} \int_{a}^{b}(-1)^{(k+1)+h-1} u^{(k+1, h)}(s, t)\left(G^{[k+1, h]}(s, t)-F^{[k+1, h]}(s, t)\right) d s d t,
\end{aligned}
$$

which shows that an identical formula prevails at orders $k$ and $k+1$ on wealth. By extension, we have:

$$
\begin{aligned}
\int_{a}^{b} & \int_{a}^{b} u(s, t)(d F(s, t)-d G(s, t)) d s d t= \\
& \int_{a}^{b} \int_{a}^{b}(-1)^{n_{1}+n_{2}-1} u^{\left(n_{1}, n_{2}\right)}(s, t)\left(G^{\left[n_{1}, n_{2}\right]}(s, t)-F^{\left[n_{1}, n_{2}\right]}(s, t)\right) d s d t .
\end{aligned}
$$


Therefore,

$$
\begin{aligned}
& T_{u} \geq T_{v} \Leftrightarrow \\
& \frac{\int_{a}^{b} \int_{a}^{b}(-1)^{n_{1}+n_{2}-1} u^{\left(n_{1}, n_{2}\right)}(s, t)\left(G^{\left[n_{1}, n_{2}\right]}(s, t)-F^{\left[n_{1}, n_{2}\right]}(s, t)\right) d s d t}{\int_{a}^{b} \int_{a}^{b}(-1)^{m_{1}+m_{2}-1} u^{\left(m_{1}, m_{2}\right)}(s, t)\left(H^{\left[m_{1}, m_{2}\right]}(s, t)-F^{\left[m_{1}, m_{2}\right]}(s, t)\right) d s d t} \geq \\
& \quad \frac{\int_{a}^{b} \int_{a}^{b}(-1)^{n_{1}+n_{2}-1} v^{\left(n_{1}, n_{2}\right)}(s, t)\left(G^{\left[n_{1}, n_{2}\right]}(s, t)-F^{\left[n_{1}, n_{2}\right]}(s, t)\right) d s d t}{\int_{a}^{b} \int_{a}^{b}(-1)^{m_{1}+m_{2}-1} v^{\left(m_{1}, m_{2}\right)}(s, t)\left(H^{\left[m_{1}, m_{2}\right]}(s, t)-F^{\left[m_{1}, m_{2}\right]}(s, t)\right) d s d t}
\end{aligned}
$$

Next, we assume that $(i)$ does not hold: we can find two compact sets $[c, d]^{2}$ and $[e, f]^{2}$ and $\mu>0$ such that

$$
\frac{u^{\left(n_{1}, n_{2}\right)}(s, t)}{v^{\left(n_{1}, n_{2}\right)}(s, t)}<\mu<\frac{u^{\left(m_{1}, m_{2}\right)}(w, z)}{v^{\left(m_{1}, m_{2}\right)}(w, z)}
$$

for all $(s, t) \in[c, d]^{2}$ and $(w, z) \in[e, f]^{2}$.

Because we assume that $v$ is $\left(n_{1}, n_{2}\right)^{\text {th }}$ and $\left(m_{1}, m_{2}\right)^{\text {th }}$ degree risk averse, we have:

$$
(-1)^{n_{1}+n_{2}-1} u^{\left(n_{1}, n_{2}\right)}(s, t)<\mu(-1)^{n_{1}+n_{2}-1} v^{\left(n_{1}, n_{2}\right)}(s, t)
$$

for all $(s, t) \in[c, d]^{2}$ and

$$
(-1)^{m_{1}+m_{2}-1} u^{\left(m_{1}, m_{2}\right)}(w, z)>\mu(-1)^{m_{1}+m_{2}-1} v^{\left(m_{1}, m_{2}\right)}(w, z)
$$

for all $(w, z) \in[e, f]_{\tilde{F}}^{2}$

Then, choosing $\tilde{F}, \tilde{G}$ and $\tilde{H}$ such that $\tilde{G}-\tilde{F}>0$ on $[c, d]^{2}, \tilde{H}-\tilde{F}>0$ on $[e, f]^{2}$ and such that these two differences are null outside the compact sets, we can write:

$$
\begin{gathered}
\int_{a}^{b} \int_{a}^{b}(-1)^{n_{1}+n_{2}-1} u^{\left(n_{1}, n_{2}\right)}(s, t)\left(\tilde{G}^{\left[n_{1}, n_{2}\right]}(s, t)-\tilde{F}^{\left[n_{1}, n_{2}\right]}(s, t)\right) d s d t< \\
\mu \int_{a}^{b} \int_{a}^{b}(-1)^{n_{1}+n_{2}-1} v^{\left(n_{1}, n_{2}\right)}(s, t)\left(\tilde{G}^{\left[n_{1}, n_{2}\right]}(s, t)-\tilde{F}^{\left[n_{1}, n_{2}\right]}(s, t)\right) d s d t
\end{gathered}
$$

and

$$
\begin{gathered}
\int_{a}^{b} \int_{a}^{b}(-1)^{m_{1}+m_{2}-1} u^{\left(m_{1}, m_{2}\right)}(s, t)\left(\tilde{H}^{\left[m_{1}, m_{2}\right]}(s, t)-\tilde{F}^{\left[m_{1}, m_{2}\right]}(s, t)\right) d s d t> \\
\mu \int_{a}^{b} \int_{a}^{b}(-1)^{m_{1}+m_{2}-1} v^{\left(m_{1}, m_{2}\right)}(s, t)\left(\tilde{H}^{\left[m_{1}, m_{2}\right]}(s, t)-\tilde{F}^{\left[m_{1}, m_{2}\right]}(s, t)\right) d s d t
\end{gathered}
$$


so that

$$
\begin{aligned}
& \frac{\int_{a}^{b} \int_{a}^{b}(-1)^{n_{1}+n_{2}-1} u^{\left(n_{1}, n_{2}\right)}(s, t)\left(\tilde{G}^{\left[n_{1}, n_{2}\right]}(s, t)-\tilde{F}^{\left[n_{1}, n_{2}\right]}(s, t)\right) d s d t}{\int_{a}^{b} \int_{a}^{b}(-1)^{m_{1}+m_{2}-1} u^{\left(m_{1}, m_{2}\right)}(s, t)\left(\tilde{H}^{\left[m_{1}, m_{2}\right]}(s, t)-\tilde{F}^{\left[m_{1}, m_{2}\right]}(s, t)\right) d s d t}< \\
& \quad \frac{\int_{a} \int_{a}^{b}(-1)^{n_{1}+n_{2}-1} v^{\left(n_{1}, n_{2}\right)}(s, t)\left(\tilde{G}^{\left[n_{1}, n_{2}\right]}(s, t)-\tilde{F}^{\left[n_{1}, n_{2}\right]}(s, t)\right) d s d t}{\int_{a}^{b} \int_{a}^{b}(-1)^{m_{1}+m_{2}-1} v^{\left(m_{1}, m_{2}\right)}(s, t)\left(\tilde{H}^{\left[m_{1}, m_{2}\right]}(s, t)-\tilde{F}^{\left[m_{1}, m_{2}\right]}(s, t)\right) d s d t}
\end{aligned}
$$

which is a contradiction. Therefore $(i)$ holds. 